5 McLean, R. J., and Brown, R. M., Devl Biol., 36, 279-285 (1974).

Glimelius, K., Wallin, A., and Eriksson, T., Physiol. Pl., 31, 225-230 (1974).

Simons, D. H., Sfakiotakis, E., and Dilley, D. R., Hortscience, 7, 556-557 (1972).

Dickinson, D. B., Physiol. Pl., 20, 118-127 (1967)

Kroh, M., Labarca, C., and Loewus, F., in Pollen Development and Physiology (edit. by Heslop-Harrison, J.), 273-278 (Butterworths, London, 1971).

10 Weisenseel, M. H., and Jaffe, L. H., J. Cell Biol., 63, 368a (1974).

11 Watson, L., Knox, R. B., and Creaser, E. H., Nature, 249, 574-576 (1974).

12 Loor, F., Eur. J. Immun., 4, 210-220 (1974).

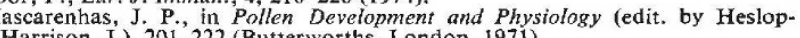
Harrison, J.), 201-222 (Butterworths, London, 1971).

W. Wh Polysaccharides, M.-S., and Loewus, M. W., York, 1973).

\section{Adaptive radiation in the subgenus Scaptodrosophila of Australian Drosophila}

UNrIL a recent survey, based on the two major museum collections of Australia ${ }^{1}$, the Australian Drosophila fauna was poorly known and few endemic species had been described. This survey covered 81 species including 40 described as new. The world total of Drosophila species is known to exceed 1,250 (ref. 2); the Australian fauna thus represents about $6 \%$ of this total. By comparison with the world Drosophila fauna, the Australian total contains a disproportionately large number of species (45 out of 81 ) in the subgenus Scaptodrosophila, most of them endemic although a few are also known from neighbouring South-east Asian and/or Pacific regions. The Australian Drosophila fauna is therefore unique in that nowhere else have members of the subgenus Scaptodrosophila so dominated the Drosophila fauna of a large region.

The three other major subgenera are poorly represented. The eleven known Australian Hirtodrosophila species are all endemic to Australia, but in the subgenera Drosophila and Sophophora, each of which contains more than 500 species worldwide ${ }^{3}$, four species only of Sophophora are endemic to Australia; these subgenera are represented in Australia principally by the cosmopolitan species, although a few of the South-east Asian/ New Guinean species extend into northern Australia.

Of the Scaptodrosophila species, only three are endemic to south-western Australia; a further two occur in both east and west, and the remainder have southern and/or northern distributions in the eastern part of the continent only ${ }^{1}$. Laboratory culture of most species has proved very difficult, complicated by the almost complete lack of information on ecology and life histories; there are some indications that the larvae of at least some species may be leaf miners pupating in soil. Equally, phylogenetic lineages within the sugbenus are substantially unknown 1 . The Australian Scaptodrosophila radiation does not, of course, compare with the famous speciation in the subgenus Drosophila in Hawaii ${ }^{4}$, in which small area more than 350 species have already been described-about four times the total number of known Australian species in the genus Drosophila and seven times the number of known Australian Scaptodrosophila; but the Hawaiian proliferation is a special case unmatched in any other comparably small region of the world.

The major Scaptodrosophila radiation in Australia has thus occurred in the eastern part of the continent, and within this region many of the species seem to be restricted to the southern part of the country (especially Victoria and New South Wales). One of the more common species is D. inornata Malloch, which is frequently closely associated with tree ferns (Dicksonia spp. $)^{5}$. The most favourable habitats for Drosophila species in south-eastern Australia seem to be wet sclerophyll/rain forest areas characterised by tree ferns and various other ferns. All habitats, including a few sheltered habitats without tree ferns, have permanent water, and often a deep layer of rotting leaf litter ${ }^{6}$. Most of the Scaptodrosophila species are not attracted to baits and so far can only be collected by intensive sweeping.

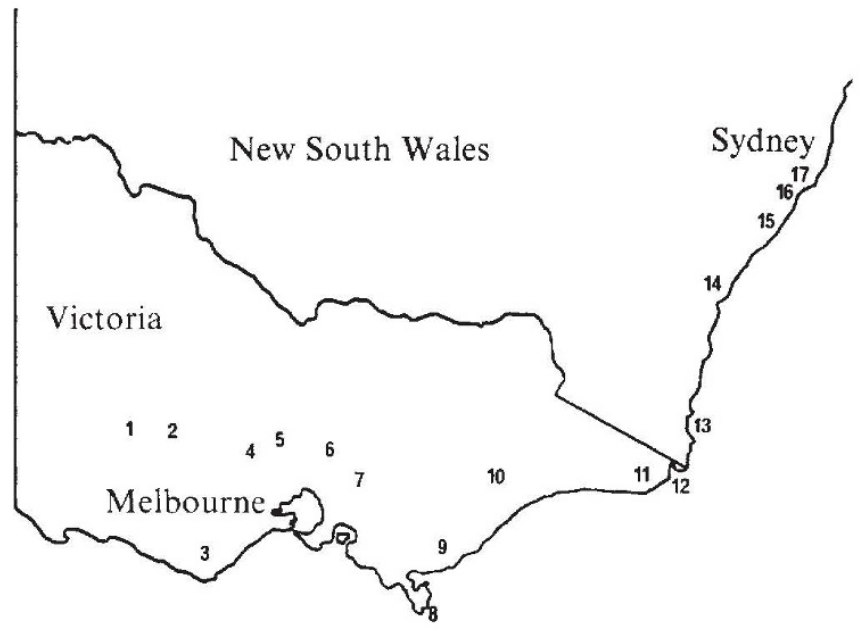

Fig. 1 Map of Victoria and south-eastern New South Wales indicating continental islands where endemic Drosophila spp. have been found.

Extensive spring and summer collections have recently been made in habitats of the above type in Victoria and the east coast of southern New South Wales (Fig. 1). More than 2,000 Scaptodrosophila representing at least twelve species, at least two of them new, were collected in damp habitats. Locality records of the museum collections ${ }^{1}$ reveal the likelihood that most of the remaining known species are confined to damp habitats. It seems likely in view of the number of sites at which collections are still to be made that further species await discovery; in any case species once regarded as extremely rare are now known to be relatively common and widespread.

The damp habitats most favourable to Scaptodrosophila species are normally isolated from one another, often by considerable distances. Localities of major habitats sampled so far are indicated in Fig. 1. The temperature/humidity requirements of the flies are such that migration among many of the habitats in summer, especially in Victoria, must be impossible ${ }^{6}$. This is because Victoria has a hot dry summer during which the habitats are damp, cool refuges, offering temperaturehumidity conditions compatible with survival of Drosophila species, but outside these refuges the environmental stress would be excessive. (Similar environmental constraints occur for the cosmopolitan species ${ }^{7}$.) There is, therefore, the possibility of studying the evolutionary biology of Scaptodrosophila species in essentially continental islands which have probably been separated for at least $6,000 \mathrm{yr}$, that is after the end of an era of high precipitation, high temperature and high rainfall ${ }^{8}$.

P.A.P. was supported by the Australian Research Grants Committee.

Department of Zoology,

James Cook University of North Queensland,

Townsville, Queensland 4811

Department of Genetics and Human Variation,

P. A. Parsons

La Trobe University,

Bundoora, Victoria 3083 ,

Australia

Received August 28; accepted October 20, 1975

Bock, I. R., Aust. J. Zool. (in the press)

Wheer. M R and Hamiln, 7213, 257-268 (1972).

3 Spieth, H. T., and Heed, W. B., A. Rev. Ecol. Syst., 3, 269-288 (1972).

Hardy, D. E., in Genetic Mechanisms of Speciation in Insects (edit. by White, M. J. D.), 71-80 (Australian and New Zealand Book Co., Sydney, 1974)

Grossfield, J., and Parsons, P. A., Proc. R. Soc. Victoria (in the press).

Bock, I. R., and Parsons, P. A., Proc. R. Soc. Victuria (in the press).

Mckenzie, J. A., and Parsons, P. A., Alust. J. Zool., 22, 175-187 (1974). Williams, W. D.), 291-338 (Junk, The Hague, 1974). 